Research Paper

\title{
Semi-scale production of PHAs from waste frying oil by Pseudomonas fluorescens S48
}

\author{
Rawia F. Gamal, Hemmat M. Abdelhady, Taha A. Khodair, Tarek S. El-Tayeb, Enas A. \\ Hassan, Khadiga A. Aboutaleb \\ Department of Agricultural Microbiology, Faculty of Agriculture, Ain Shams University, Shoubra \\ El-Kheima, Cairo, Egypt.
}

Submitted: June 23, 2011; Approved: June 5, 2012.

\begin{abstract}
The present study aimed at developing a strategy to improve the volumetric production of PHAs by Pseudomonas fluorescens S48 using waste frying oil (WFO) as the sole carbon source. For this purpose, several cultivations were set up to steadily improve nutrients supply to attain high cell density and high biopolymer productivity. The production of PHAs was examined in a $14 \mathrm{~L}$ bioreactor as one-stage batch, two-stage batch, and high-cell-density fed-batch cultures. The highest value of polymer content in one-stage bioreactor was obtained after $60 \mathrm{~h}(33.7 \%)$. Whereas, the two-stage batch culture increased the polymer content to $50.1 \%$ after $54 \mathrm{~h}$. High-cell-density $(0.64 \mathrm{~g} / \mathrm{L})$ at continuous feeding rate $0.55 \mathrm{~mL} / \mathrm{l} / \mathrm{h}$ of $\mathrm{WFO}$ recorded the highest polymer content after $54 \mathrm{~h}(55.34 \%)$. Semi-scale application (10 L working volume) increased the polymer content in one-stage batch, two-stage batch and high cell density fed-batch cultures by about $12.3 \%, 5.8 \%$ and $11.3 \%$, respectively, as compared with that obtained in $2 \mathrm{~L}$ fermentation culture. Six different methods for biopolymer extraction were done to investigate their efficiency for optimum polymer recovery. The maximum efficiency of solvent recovery of PHA was attained by chloroform-hypochlorite dispersion extraction. Gas chromatography (GC) analysis of biopolymer produced by Pseudomonas fluorescens S48 indicated that it solely composed of 3-hydrobutyric acid (98.7\%). A bioplastic film was prepared from the obtained PHB. The isolate studied shares the same identical sequence, which is nearly the complete $16 \mathrm{~S}$ rRNA gene. The identity of this sequence to the closest pseudomonads strains is about $98-99 \%$. It was probably closely related to support another meaningful parsiomony analysis and construction of a phylogenetic tree. The isolate is so close to Egyptian strain named EG 639838.
\end{abstract}

Key words: Pseudomonas fluorescens S48, biopolymer, PHAs, batch, two-stage batch, high-celldensity fed batch, bioreactor, recovery.

\section{Introduction}

Plastic materials have become an integral part of contemporary life because of many desirable properties including durability and resistance to degradation. The non-degradable plastics accumulate in the environment with an increasing rate. Recently, the problems concerning the global environment and solid waste management have created much interest in the development of biodegradable plastics, which must still retain the desired physical and chemical properties of conventional synthetic plastics. One of the biodegradable plastic materials under development includes polyhydroxyalkanoates (PHAs) (Slater et al., 1998). However, one of the problems facing the development of biodegradable polymers as substitutes for conventional plastics is their high price compared with petrochemical derived plastics. Therefore, many efforts have been made to reach low-cost PHA production processes (Verlinden et al., 2007). Different potent strains, which grow to high-celldensity in cheap cultivation media and accumulating high

Send correspondence to T.S. El-Tayeb. Department of Agricultural Microbiology, Faculty of Agriculture, Ain Shams University, 11241 Shoubra El-Kheima, Cairo, Egypt. E-mail: tarekeltayeb@yahoo.com. 
PHA content via cost-efficient fermentation process and enabling easy recovery methods as well, were described in numerous investigations and patented processes (Kinoshita et al., 2005). Since one of the main obstacles that hinder an economic feasible production of PHA is the cost of carbon substrate $(25 \%$ to $28 \%$ of total production cost). However, the abundance of inexpensive waste materials from agriculture, industry or agro-industrial such as waste frying oil present them as an alternative cheap substrates for microbial fermentations, in particular for the production of microbial polyesters (Da Silva et al., 2009).

Either fed-batch or continuous cultivation techniques can be used for the production of PHA with high productivity. Fed-batch culture has been the most popular culture system to achieve a high cell density and PHB content (Kim et al., 1994; Lee and Yoo, 1994; Kim et al., 2003; Valappil et al., 2007). In this system, it is essential to maintain optimal concentration of nutrients during fermentation. This can be achieved by using various feeding strategies (Lee $e t$ al., 1997; Wang and Lee, 1997; Abdel Hafez et al., 2009; Lopez-Cuellar et al., 2011).

In view of these facts, the current investigation is aimed to study the semi-scale production of PHAs from waste frying oil using different fermentation techniques as batch and two-stage batch and high-cell-density fed-batch cultures in $14 \mathrm{~L}$ bioreactor.

\section{Materials and Methods}

\section{Microorganism and culture conditions}

Pseudomonas fluorescens S48 was used in this investigation for accumulating PHAs from waste frying oil (WFO) (Gamal et al., 2011, 2012). The bacterial culture was maintained by transferring at regular intervals on nutrient agar slants. Slants were kept at $4{ }^{\circ} \mathrm{C}$ until used. For PHAs production, the bacterium was grown in basal medium modified by Gamal et al. (2012) called productive medium containing $(\mathrm{g} / \mathrm{L}):\left(\mathrm{NH}_{4}\right)_{2} \mathrm{SO}_{4} 1.0, \mathrm{KH}_{2} \mathrm{PO}_{4} 1.5$, $\mathrm{Na}_{2} \mathrm{HPO}_{4} .12 \mathrm{H}_{2} \mathrm{O} 9.0, \mathrm{MgSO}_{4} .7 \mathrm{H}_{2} \mathrm{O} 0.2,1 \mathrm{~mL}$ of trace elements solution $\left(\mathrm{FeSO}_{4} .7 \mathrm{H}_{2} \mathrm{O} \quad 10, \mathrm{ZnSO}_{4} .7 \mathrm{H}_{2} \mathrm{O} \quad 2.25\right.$, $\mathrm{CuSO}_{4} .5 \mathrm{H}_{2} \mathrm{O} \quad 1.0, \mathrm{MnSO}_{4} \cdot 4 \mathrm{H}_{2} \mathrm{O} \quad 0.5, \mathrm{CaCl}_{2} .2 \mathrm{H}_{2} \mathrm{O} \quad 2.0$, $\mathrm{Na}_{2} \mathrm{~B}_{4} \mathrm{O}_{7} .10 \mathrm{H}_{2} \mathrm{O} 0.23,\left(\mathrm{NH}_{4}\right)_{6} \mathrm{Mo}_{7} \mathrm{O}_{24} 0.1$ and $35 \% \mathrm{HCl}$ $10 \mathrm{~mL}$ ) and $10 \mathrm{~mL}$ waste frying oil as the sole carbon source. The $\mathrm{pH}$ was adjusted to 7.0 before sterilization.

Cultivation was done in a Bioflo 3000 14-liter fermenter (New Brunswick Scientific Co., Inc. Edison, NJ 08818-4005 USA), with a working volume of 10 liter (24 cm inner diameter and $45 \mathrm{~cm}$ height) and a d/D value (relation of stirrer diameter to vessel diameter) of 0.286 was used for cultivation. The bioreactor was equipped with three stirrers, each containing six paddles and a Fundafoam mechanical destroyer. In addition, sterilizable probes were inserted into ports to measure dissolved oxygen, $\mathrm{pH}$ and temperature. The operation were controlled and recorded. Cultivation was carried out at $30{ }^{\circ} \mathrm{C}$ and
$350 \mathrm{mM} / \mathrm{L} / \mathrm{h}$ oxygen transfer rate obtained through powerful fermentation agitation motor and 6-bladed Rushton impellers dissolve $20 \%$ air saturation in the medium, which was controlled by agitation at $500 \mathrm{rpm}$ and aeration rate $1 \mathrm{vvm}$. Unless otherwise stated, the $\mathrm{pH}$ of medium was adjusted at $7.0 \pm 1$ by the controlled addition of $\mathrm{NaOH}(5 \mathrm{~N})$ or $4 \mathrm{~N} \mathrm{HCl}$. The operations were controlled and recorded by a digital control unit (DCU) in combination with the software package. Samples of $10-20 \mathrm{~mL}$ were withdrawn from the culture fluid for analytical purposes.

\section{Bioreactor as a one-stage batch culture}

In this experiment the fermentation vessel (bioreactor) containing $9800 \mathrm{~mL}$ productive medium without WFO was autoclaved at $121^{\circ} \mathrm{C}$ for $40 \mathrm{~min}$. WFO (1\%) was added after sterilization. The fermentation medium was inoculated with $1 \%$ standard inoculum of the bacterial strain. The standard inoculum was prepared in a conical flask $(250 \mathrm{~mL})$ containing $100 \mathrm{~mL}$ of nutrient broth medium inoculated with a loop of Ps. fluorescens S48 and incubated at $28-30{ }^{\circ} \mathrm{C}$ with shaking (300 rpm) for $24 \mathrm{~h}$ prior to inoculation $\left(5 \times 10^{8} \mathrm{cfu} / \mathrm{mL}\right)$.

The final working volume was 10 liter. Initial $\mathrm{pH}$ was adjusted to $7 \pm 0.1$ which was not controlled during the fermentation period. Temperature, dissolved $\mathrm{O}_{2}$ and speed of agitation were kept at $30{ }^{\circ} \mathrm{C}, 20 \%$ of air saturation and $500 \mathrm{rpm}$, respectively, during cultivation.

During fermentation, samples $(10-20 \mathrm{~mL})$ were withdrawn from the culture (fermentation vessel) periodically. The samples were centrifuged at $15000 \mathrm{xg}$ for $4 \mathrm{~min}$ at $4{ }^{\circ} \mathrm{C}$. The sediment (biomass) was washed twice with distilled water, and then dried at $70{ }^{\circ} \mathrm{C}$ to constant weight.

\section{Bioreactor as a two-stage batch culture}

The production of PHAs was carried out in two-stage cultivation. In the first stage, two sterile conical flasks $(1000 \mathrm{~mL})$ each containing $400 \mathrm{~mL}$ nutrient medium was inoculated with $10 \mathrm{~mL}$ standard inoculum of the bacterial strain, then incubated at $30{ }^{\circ} \mathrm{C}$ for $24 \mathrm{~h}$ on rotary shaker $(150 \mathrm{rpm})$ in order to get a luxurious growth. Then the culture fluid was centrifuged at $15000 \mathrm{xg}$ for $4 \mathrm{~min}$ at $4{ }^{\circ} \mathrm{C}$ and the bacterial cells were collected and suspended in additional sterile productive medium to inoculate the bioreactor vessel to give a final working volume of $10 \mathrm{~L}$ sterile productive medium. The cultivation conditions and microbiological determinations were done as mentioned before.

\section{Bioreactor as high-cell-density fed-batch culture}

This experiment of fed-batch culture was constructed to study the effect of washed high-cell-densities $(0.64 \mathrm{~g} / \mathrm{L})$ of Ps. fluorescens S48 on PHAs production. WFO was fed continuously at $0.55 \mathrm{~mL} / \mathrm{L} / \mathrm{h}$ during the first $18 \mathrm{~h}$ of cultivation (according to the obtained results from Gamal et al. (2012) for the semi-scale production. Samples (10-20 mL) were taken from the growing culture periodically under 
aseptic conditions to determine the cell dry weight, PHAs produced and residual carbon.

In all cultivations, polymer in samples was generally precipitated and determined as dry weight and PHAs content was determined as dry weight percent. The extraction of PHAs was implemented by the chloroform-sodium hypochlorite method (Hahn et al., 1994). Total organic carbon was determined in supernatant according to Walinga et al. (1992). Polymer content (\%) and productivity $(\mathrm{g} / \mathrm{L} / \mathrm{h})$ were calculated according to Lee and Choi (1998) and Lee (1996), respectively. The parameters of polymer yield (\%), conversion coefficient (\%) and carbon utilization efficiency (\%) were calculated according to Ramadan et al. (1985).

\section{PHAs recovery}

Six different methods for bioplastic recovery were performed as the following:

\section{Biopolymer recovery by commercial sodium hypochlorite solution}

The culture fluid was centrifuged in polypropylene centrifuge tubes which had been previously washed thoroughly with ethanol and hot chloroform to remove plasticizers. The cell paste was resuspended in a volume of commercial sodium hypochlorite solution (clorox or equivalent) equal to the original volume of medium. After $1 \mathrm{hr}$ at $37^{\circ} \mathrm{C}$ the lipid granules were centrifuged, washed with water, and then washed with acetone and alcohol. Finally, the polymer was dissolved by extraction with three small portions of boiling chloroform, the chloroform solution was filtered, and the filtrate was used for biopolymer assay (Law and Slepecky, 1961).

\section{Biopolymer recovery by using dispersions of sodium hypochlorite and chloroform}

A $1 \mathrm{~g}$ portion of freeze-dried cells was treated with a dispersion containing $50 \mathrm{~mL}$ of chloroform and $50 \mathrm{~mL}$ of a diluted sodium hypochlorite solution ( $3 \% \mathrm{vol} / \mathrm{vol})$. After the cells were treated at $30^{\circ} \mathrm{C}$ for $1 \mathrm{~h}$, the mixture was centrifuged at $4000 \mathrm{xg}$ for $10 \mathrm{~min}$, which resulted in three separate phases. The upper phase was a hypochlorite solution, the middle phase contained non-PHB cell material and undisrupted cells, and the bottom phase was chloroform containing PHB. The upper phase was removed first with a pipette, and the middle phase was separated by filtration from the chloroform phase. Finally, bottom phase was chloroform containing PHB. PHB was recovered from the chloroform phase by nonsolvent precipitation (mixture of methanol and water 7:3, vol/vol) five times the volume of chloroform and filtration (Hahn et al., 1994).

\section{Biopolymer recovery by using acetone and chloroform}

Freeze-dried cell powder was washed with hot acetone for $20 \mathrm{~min}$. After drying, the cell powder was mixed with 50 volumes of chloroform for $48 \mathrm{~h}$ at $30^{\circ} \mathrm{C}$. The clear polymer solution was recovered by centrifugation to remove the majority of the non-PHB cell material; this was followed by polishing filtration. Finally, pure biopolymer was obtained by no solvent precipitation (five times the volume of chloroform) and filtration. The nonsolvent used was a mixture of methanol and water 7:3 ( $\mathrm{vol} / \mathrm{vol})(\mathrm{Hahn}$ et al., 1995).

\section{Biopolymer recovery by sodium hypochlorite}

A sodium hypochlorite solution was diluted with distilled water to give concentrations $3 \%$ (vol/vol). The biomass was mixed with a hypochlorite solution, Biopolymer granules were separated from the aqueous fraction containing cell debris by centrifugation. The Polymer recovered was rinsed with distilled water, centrifuged again, and then rinsed with acetone. $1 \%(\mathrm{wt} / \mathrm{vol})$ biomass suspension was treated for $1 \mathrm{~h}$ at $30^{\circ} \mathrm{C}$ (Hahn et al., 1995).

\section{Biopolymer recovery by using chloroform}

Lyophilized cell pellets were ground in a mortar and the resulting powder was extracted with chloroform for $4 \mathrm{~h}$ at $50{ }^{\circ} \mathrm{C}$. The PHA-containing chloroform phase was concentrated and extracted once with water to remove residual solid particles. The organic phase was evaporated to dryness and the resulting crude extract preserved for further analyses. Purified PHAs were obtained by repeated precipitations in 10 volumes of cold methanol (Simon-Colin et al., 2008).

\section{Biopolymer recovery by using sodium dodecyl sulfate (SDS)}

The cells were harvested and treated with $10 \%$ SDS at $100{ }^{\circ} \mathrm{C}$ for $20 \mathrm{~min}$. After centrifugation, the pellets were washed, dried and extracted with chloroform at $60{ }^{\circ} \mathrm{C}$ for $1 \mathrm{~h}$. The non-PHB cell matter was removed by filtration and the dissolved PHB was separated from chloroform by evaporation, washed twice with methanol, filtered out and dried at $60-70{ }^{\circ} \mathrm{C}$ (Jiang et al., 2008).

\section{$\mathrm{GC}$ analysis of biopolymer composition}

Composition of PHA was determined by GC as described by Mumtaz et al. (2009).

\section{Preparation of a biopolymer film}

Totally $250 \mathrm{mg}$ of PHB was dissolved in $28 \mathrm{~mL}$ chloroform. The solution was evenly distributed into 5 petri dishes. The dishes were maintained at $30^{\circ} \mathrm{C}$ to allow complete evaporation of chloroform. The evaporation of solvent resulted in formation of PHB films in the petri dishes. Vacuum drying was further applied to completely remove any possible solvent remained in the films (Kai et al., 2003).

\section{DNA extraction and PCR amplification}

The bacteria were grown in nutrient broth on a rotary shaker $(120 \mathrm{rpm})$ at $20{ }^{\circ} \mathrm{C}$ for $24 \mathrm{~h}$. Bacterial Genomic 
DNA Mini-Prep Kit (Axygen cat. No. V110440-05) was used to isolate DNA as advised by the manufacturer. The universal $16 \mathrm{~S}$ primers used were: F1 5, AGAGTTT(G/C)ATCCTGGCTCAG 3' R1 5' ACGG(A/C)TACCTTGTTACGACTT 3'

Primers were checked for specificity using the PROBE CHECK function of the Ribosomal Database and the BLAST search facility at the National Center for Biotechnology Information. DNA amplification was conducted on pure 2 to $3 \mu \mathrm{L}$ DNA sample with about $150 \mathrm{ng}$ of DNA per $1 \mu \mathrm{L}$ of sample in a perkin Elmer 2400 (Nowalk, $\mathrm{CT})$ thermocycler. The F1 and R1 primers amplifying the PCR reactions were added with a final volume of $100 \mu \mathrm{L}$ with $0.2 \mu \mathrm{M}$ of each primer, $2.0 \mathrm{mM} \mathrm{MgCl}, 200 \mu \mathrm{M}$ dNTPs and 2.5 units of Maxima ${ }^{\circledR}$ Hot start Taq DNA Polymerase (Fermentas, www.fermentas.com) mixed in the 1X PCR buffer. DNA was amplified over 35 cycles of denaturation for $1 \mathrm{~min}$ at $94{ }^{\circ} \mathrm{C}$, annealing at $55^{\circ} \mathrm{C}$ for $1.5 \mathrm{~min}$ and extension at $72{ }^{\circ} \mathrm{C}$ for $2 \mathrm{~min}$. After the last cycle, DNA was extended at $72{ }^{\circ} \mathrm{C}$ for $10 \mathrm{~min}$. Amplification was confirmed by analyzing $5 \mu \mathrm{L}$ of PCR reaction mixture on $1 \%$ agarose gel (Promega). The resulting PCR products sizes were ranged from 1450 to $1500 \mathrm{bp}$.

\section{DNA sequencing}

The PCR-product was purified using QIAquik PCR Purification Kit (Qiagen), and sequenced using automatic ABI 310 DNA Sequencer, Big Dye Terminator Cycle Sequencing Ready Reaction Kit, Perkin Elmer. The sequencing was performed in one direction using one of the previously described primers (Lane, 1991; Lane et al., 1985). Sequencing data was analyzed by two different computer alignment programs, DNAStar (DNASTAR, Inc., USA) and Sequence Navigator (Perkin, Corp., USA).

\section{Determination of phylogenetic relationships}

The BLAST database (Altschul et al., 1997) of National Center for Biotechnology Information was used to compare resolved sequence of the Ps. fluorescens $\mathrm{S} 48$ with known 16S rDNA sequences. Determination of phylogenetic relationships was analyzed by the program Phylogenetic Analysis megAlign of DNAstar version 7.0. The robustness of the internal branches of the trees was estimated by bootstrap analyses using 1000 replications in a heuristic search with random stepwise addition (111 replications) (Vinnere et al., 2002). Bootstrap majority-rule (> 50\%) consensus trees were obtained.

\section{Statistical analysis}

The collected data were statistically analyzed using IBM $^{\circledR}$ SPSS $^{\circledR}$ Statistics software (2011).

\section{Results and discussion}

\section{Semi-scale production of PHAs}

The successful production of PHAs in both shaken flasks (Gamal et al., 2011) and $3 \mathrm{~L}$ laboratory fermentor (Gamal et al., 2012) cultures generate the trials of semiscale production of PHAs in $14 \mathrm{~L}$ laboratory fermentor cultures. Different fermentation techniques were applied in order to increase the PHAs yield using WFO as the sole carbon source.

\section{One-stage batch culture}

In batch culture, the cell mass increased gradually leading to record the maximum values of cell dry weight and polymer concentration $(2.93$ and $0.92 \mathrm{~g} / \mathrm{L}$, respectively) after $72 \mathrm{~h}$ of cultivation (Table 1). Whereas, the maximum PHAs content (33.7\%) was obtained after $60 \mathrm{~h}$

Table 1 - Semi-scale production of PHAs by Ps. fluorescens S48 on productive medium containing WFO (waste frying oil) as carbon source throughout $72 \mathrm{~h}$ at $30^{\circ} \mathrm{C}$ using bioreactor as a batch culture.

\begin{tabular}{|c|c|c|c|c|c|c|c|}
\hline Time (h) & $\begin{array}{c}\text { Cell dry weight } \\
(\mathrm{g} / \mathrm{L})\end{array}$ & $\begin{array}{l}\text { PHAs concentration } \\
\qquad(\mathrm{g} / \mathrm{L})\end{array}$ & $\begin{array}{l}\text { Residual cells } \\
(\mathrm{g} / \mathrm{L})\end{array}$ & $\begin{array}{c}\text { PHAs content } \\
(\%)\end{array}$ & $\begin{array}{l}\text { PHAs productivity } \\
(\mathrm{g} / \mathrm{L} / \mathrm{h})\end{array}$ & $\begin{array}{c}\text { PHAs synthesis } \\
\text { rate }(\mathrm{g} / \mathrm{g} / \mathrm{h})\end{array}$ & Final $\mathrm{pH}$ \\
\hline 0 & $0.15^{\mathrm{j}}$ & $0.00^{\mathrm{i}}$ & $0.15^{\mathrm{j}}$ & $0.00^{\mathrm{i}}$ & $0.000^{g}$ & $0.000^{\mathrm{g}}$ & $7.1^{\mathrm{c}}$ \\
\hline 6 & $0.17^{\mathrm{i}}$ & $0.00^{\mathrm{i}}$ & $0.17^{\mathrm{i}}$ & $0.00 \mathrm{i}$ & $0.000^{\mathrm{g}}$ & $0.000^{\mathrm{g}}$ & $6.9^{\mathrm{d}}$ \\
\hline 12 & $0.25^{\mathrm{h}}$ & $0.04^{\mathrm{h}}$ & $0.21^{\mathrm{h}}$ & $16.00^{\mathrm{h}}$ & $0.003^{\mathrm{f}}$ & $0.016^{\mathrm{a}}$ & $6.8^{\mathrm{e}}$ \\
\hline 24 & $1.15^{\mathrm{g}}$ & $0.19^{\mathrm{g}}$ & $0.96^{\mathrm{g}}$ & $16.52^{g}$ & $0.008^{\mathrm{e}}$ & $0.008^{\mathrm{e}}$ & $6.9^{\mathrm{d}}$ \\
\hline 30 & $1.38^{\mathrm{f}}$ & $0.31^{\mathrm{f}}$ & $1.07^{\mathrm{f}}$ & $22.46^{\mathrm{f}}$ & $0.010^{\mathrm{d}}$ & $0.010^{\mathrm{c}}$ & $7.1^{\mathrm{c}}$ \\
\hline 36 & $1.56^{\mathrm{e}}$ & $0.45^{\mathrm{e}}$ & $1.11^{\mathrm{e}}$ & $28.48^{\mathrm{e}}$ & $0.013^{\mathrm{b}}$ & $0.011^{\mathrm{b}}$ & $7.2^{\mathrm{b}}$ \\
\hline 48 & $1.99^{\mathrm{d}}$ & $0.59^{\mathrm{d}}$ & $1.40^{\mathrm{d}}$ & $29.65^{\mathrm{d}}$ & $0.012^{\mathrm{c}}$ & $0.009^{\mathrm{d}}$ & $7.2^{\mathrm{b}}$ \\
\hline 54 & $2.65^{\mathrm{c}}$ & $0.79^{\mathrm{c}}$ & $1.86^{\mathrm{b}}$ & $29.81^{\mathrm{c}}$ & $0.015^{\mathrm{a}}$ & $0.008^{\mathrm{e}}$ & $7.3^{\mathrm{a}}$ \\
\hline 60 & $2.74^{\mathrm{b}}$ & $0.91^{\mathrm{b}}$ & $1.83^{\mathrm{c}}$ & $33.70^{\mathrm{a}}$ & $0.015^{\mathrm{a}}$ & $0.008^{\mathrm{e}}$ & $7.2^{\mathrm{b}}$ \\
\hline 72 & $2.93^{\mathrm{a}}$ & $0.92^{\mathrm{a}}$ & $2.01^{\mathrm{a}}$ & $31.72^{\mathrm{b}}$ & $0.013^{\mathrm{b}}$ & $0.006^{\mathrm{f}}$ & $7.3^{\mathrm{a}}$ \\
\hline
\end{tabular}

PHAs content $(\%)=$ Polymer concentration $(\mathrm{g} / \mathrm{L}) /$ cell dry weight $(\mathrm{g} / \mathrm{L}) \mathrm{x} 100$.

PHAs productivity $(\mathrm{g} / \mathrm{L} / \mathrm{h})=$ Polymer concentration $(\mathrm{g} / \mathrm{L}) /$ fermentation time $(\mathrm{h})(\mathrm{Lee}, 1996)$.

PHAs synthesis rate $(\mathrm{g} / \mathrm{g} / \mathrm{h})=$ Polymer concentration $(\mathrm{g} / \mathrm{L}) /$ residual cells $(\mathrm{g} / \mathrm{L}) /$ fermentation time $(\mathrm{h})$ (Ramadan et al., 1985).

Values in the same column followed by the same letter do not significantly differ from each other, according to Duncan's at $5 \%$ level. 
fermentation period. The corresponding figures of polymer synthesis rate and productivity were $0.008 \mathrm{~g} / \mathrm{g} / \mathrm{h}$ and $0.015 \mathrm{~g} / \mathrm{L} / \mathrm{h}$, respectively. A slight decrease was observed on $\mathrm{pH}$ values during the first $12 \mathrm{~h}$ of growth (7.1 to 6.8), and then increased to 7.3 at the end of fermentation period. Data recorded in Table 2 revealed, that the highest values of utilized carbon (UC), PHAs yield and carbon utilization efficiency (CUE) being $6.12 \mathrm{~g} / \mathrm{L}, 12.11 \%$ and $80.53 \%$, respectively, were obtained after $72 \mathrm{~h}$. Whereas, the highest conversion coefficient and specific production rate of PHAs were recorded after 60 and $24 \mathrm{~h}$ fermentation period $\left(15.22 \%\right.$ and $0.13 \mathrm{~h}^{-1}$, respectively).

\section{Two-stage batch culture}

Data presented in Tables 3 and 4 indicated that the cell dry weight of Ps. fluorescens S48 and PHAs concentration were increased gradually during the second stage of cultivation (production stage) to record the maximum values $(5.42$ and $2.60 \mathrm{~g} / \mathrm{L})$ after $72 \mathrm{~h}$ in productive medium containing $1 \%$ WFO as the sole carbon source. The highest values of PHAs content $(50.10 \%)$ was obtained after $54 \mathrm{~h}$, whereas, the highest values of polymer synthesis rate and productivity were obtained after $36 \mathrm{~h}(0.025 \mathrm{~g} / \mathrm{g} / \mathrm{h}$ and $0.048 \mathrm{~g} / \mathrm{L}$, respectively). During fermentation period, a slight increase in $\mathrm{pH}$ value from 7.0 to 7.3 was recorded

Table 2 - Impact of time course on the PHA's parameters (CUE, yield, $\mu_{\mathrm{p}}$ and CC) produced by Ps. fluorescens S48 on productive medium containing WFO as carbon source throughout $72 \mathrm{~h}$ at $30^{\circ} \mathrm{C}$ using bioreactor as a batch culture.

\begin{tabular}{|c|c|c|c|c|c|c|c|c|}
\hline Time (h) & $\begin{array}{l}\text { Cell dry weight } \\
\qquad(\mathrm{g} / \mathrm{L})\end{array}$ & $\begin{array}{l}\text { PHAs concen- } \\
\text { tration }(\mathrm{g} / \mathrm{L})\end{array}$ & $\begin{array}{l}\text { Carbon concen- } \\
\text { tration }(\mathrm{g} / \mathrm{L})\end{array}$ & $\begin{array}{l}\text { Utilized carbon } \\
\qquad(\mathrm{g} / \mathrm{L})\end{array}$ & $\begin{array}{l}\text { Carbon utiliza- } \\
\text { tion efficiency } \\
\text { (CUE) }(\%)\end{array}$ & Yield (Y) (\%) & $\begin{array}{l}\text { Specific pro- } \\
\text { duction rate } \\
\left(\mu_{\mathrm{p}}\right)\left(\mathrm{h}^{-1}\right)\end{array}$ & $\begin{array}{c}\text { Conversion co- } \\
\text { efficient }(\mathrm{CC}) \\
(\%)\end{array}$ \\
\hline 0 & $0.15^{\mathrm{j}}$ & $0.00^{\mathrm{i}}$ & $7.60^{\mathrm{a}}$ & $0.00^{\mathrm{j}}$ & $0.00^{\mathrm{j}}$ & $0.00^{\mathrm{i}}$ & $0.000^{\mathrm{h}}$ & $0.00^{\mathrm{i}}$ \\
\hline 6 & $0.17^{\mathrm{i}}$ & $0.00^{\mathrm{i}}$ & $7.04^{\mathrm{b}}$ & $0.56^{\mathrm{i}}$ & $7.37^{\mathrm{i}}$ & $0.00^{\mathrm{i}}$ & $0.000^{\mathrm{h}}$ & $0.00^{\mathrm{i}}$ \\
\hline 12 & $0.25^{\mathrm{h}}$ & $0.04^{\mathrm{h}}$ & $6.08^{\mathrm{c}}$ & $1.52^{\mathrm{h}}$ & $20.00^{\mathrm{h}}$ & $0.53^{\mathrm{h}}$ & $0.000^{\mathrm{h}}$ & $2.63^{\mathrm{h}}$ \\
\hline 24 & $1.15^{\mathrm{g}}$ & $0.19^{\mathrm{g}}$ & $4.47^{\mathrm{d}}$ & $3.13^{\mathrm{g}}$ & $41.18^{\mathrm{g}}$ & $2.50^{\mathrm{g}}$ & $0.130^{\mathrm{a}}$ & $6.07^{\mathrm{g}}$ \\
\hline 30 & $1.38^{\mathrm{f}}$ & $0.31^{\mathrm{f}}$ & $3.62^{\mathrm{e}}$ & $3.98^{\mathrm{f}}$ & $52.37^{\mathrm{f}}$ & $4.08^{\mathrm{f}}$ & $0.114^{\mathrm{b}}$ & $7.79^{\mathrm{f}}$ \\
\hline 36 & $1.56^{\mathrm{e}}$ & $0.45^{\mathrm{e}}$ & $3.15^{\mathrm{f}}$ & $4.45^{\mathrm{e}}$ & $58.55^{\mathrm{e}}$ & $5.92^{\mathrm{e}}$ & $0.104^{\mathrm{c}}$ & $10.11^{\mathrm{e}}$ \\
\hline 48 & $1.99^{\mathrm{d}}$ & $0.59^{\mathrm{d}}$ & $2.62^{\mathrm{g}}$ & $4.98^{\mathrm{d}}$ & $65.53^{\mathrm{d}}$ & $7.76^{\mathrm{d}}$ & $0.075^{\mathrm{d}}$ & $11.85^{\mathrm{d}}$ \\
\hline 54 & $2.65^{\mathrm{c}}$ & $0.79^{\mathrm{c}}$ & $2.26^{\mathrm{h}}$ & $5.34^{\mathrm{c}}$ & $70.26^{\mathrm{c}}$ & $10.39^{\mathrm{c}}$ & $0.071^{\mathrm{e}}$ & $14.79^{\mathrm{c}}$ \\
\hline 60 & $2.74^{\mathrm{b}}$ & $0.91^{\mathrm{b}}$ & $1.62^{\mathrm{i}}$ & $5.98^{\mathrm{b}}$ & $78.68^{\mathrm{b}}$ & $11.97^{\mathrm{b}}$ & $0.065^{\mathrm{f}}$ & $15.22^{\mathrm{a}}$ \\
\hline 72 & $2.93^{\mathrm{a}}$ & $0.92^{\mathrm{a}}$ & $1.48^{\mathrm{j}}$ & $6.12^{\mathrm{a}}$ & $80.53^{\mathrm{a}}$ & $12.11^{\mathrm{a}}$ & $0.052^{\mathrm{g}}$ & $15.03^{\mathrm{b}}$ \\
\hline
\end{tabular}

Carbon utilization efficiency (\%) = Utilized carbon (g/L) / initial carbon (g/L) X 100 (Ramadan et al., 1985).

Yield $=$ PHAs $(\mathrm{g} / \mathrm{L}) /$ initial carbon $(\mathrm{g} / \mathrm{L}) \times 100$ (Ramadan et al., 1985$)$.

Productivity $(\mathrm{g} / \mathrm{L} / \mathrm{h})=$ Polymer concentration $(\mathrm{g} / \mathrm{L}) /$ fermentation time $(\mathrm{h})($ Lee, 1996$)$.

Conversion coefficient $(\%)=$ Polymer concentration $(\mathrm{g} / \mathrm{L}) /$ utilized carbon $(\mathrm{g} / \mathrm{L})$ X 100 (Ramadan et al., 1985).

Values in the same column followed by the same letter do not significantly differ from each other, according to Duncan's at $5 \%$ level.

Table 3 - Semi-scale production of PHAs by Ps. fluorescens $\mathrm{S} 48$ on productive medium containing WFO as carbon source throughout $72 \mathrm{~h}$ at $30^{\circ} \mathrm{C}$ using bioreactor as a two-stage batch culture.

\begin{tabular}{|c|c|c|c|c|c|c|c|}
\hline Time (h) & $\begin{array}{c}\text { Cell dry weight } \\
(\mathrm{g} / \mathrm{L})\end{array}$ & $\begin{array}{l}\text { PHAs concentration } \\
(\mathrm{g} / \mathrm{L})\end{array}$ & $\begin{array}{l}\text { Residual cells } \\
(\mathrm{g} / \mathrm{L})\end{array}$ & $\begin{array}{c}\text { PHAs content } \\
(\%)\end{array}$ & $\begin{array}{c}\text { PHAs productivity } \\
(\mathrm{g} / \mathrm{L} / \mathrm{h})\end{array}$ & $\begin{array}{l}\text { PHAs synthesis } \\
\text { rate }(\mathrm{g} / \mathrm{g} / \mathrm{h})\end{array}$ & Final $\mathrm{pH}$ \\
\hline 0 & $0.92^{\mathrm{j}}$ & $0.00^{\mathrm{i}}$ & $0.92^{\mathrm{g}}$ & $0.00^{\mathrm{i}}$ & $0.000^{\mathrm{h}}$ & $0.000^{\mathrm{g}}$ & $7.0^{\mathrm{d}}$ \\
\hline 6 & $1.32^{\mathrm{i}}$ & $0.00^{\mathrm{i}}$ & $1.32^{\mathrm{i}}$ & $0.00^{\mathrm{i}}$ & $0.000^{\mathrm{h}}$ & $0.000^{\mathrm{g}}$ & $7.1^{\mathrm{c}}$ \\
\hline 12 & $1.99^{\mathrm{h}}$ & $0.23^{\mathrm{h}}$ & $1.76^{\mathrm{h}}$ & $11.56^{\mathrm{h}}$ & $0.019^{\mathrm{g}}$ & $0.011^{\mathrm{f}}$ & $7.2^{\mathrm{b}}$ \\
\hline 24 & $2.94^{\mathrm{g}}$ & $0.92^{\mathrm{g}}$ & $2.02^{\mathrm{e}}$ & $31.29^{\mathrm{g}}$ & $0.038^{\mathrm{e}}$ & $0.019^{c}$ & $7.3^{\mathrm{a}}$ \\
\hline 30 & $3.12^{\mathrm{f}}$ & $1.32^{\mathrm{f}}$ & $1.80^{\mathrm{g}}$ & $42.31^{\mathrm{f}}$ & $0.044^{\mathrm{c}}$ & $0.024^{b}$ & $7.2^{\mathrm{b}}$ \\
\hline 36 & $3.64^{\mathrm{e}}$ & $1.72^{\mathrm{e}}$ & $1.92^{\mathrm{f}}$ & $47.25^{\mathrm{d}}$ & $0.048^{\mathrm{a}}$ & $0.025^{\mathrm{a}}$ & $7.1^{\mathrm{c}}$ \\
\hline 48 & $4.82^{\mathrm{d}}$ & $2.13^{\mathrm{d}}$ & $2.69^{\mathrm{b}}$ & $44.19^{\mathrm{e}}$ & $0.044^{\mathrm{c}}$ & $0.016^{\mathrm{d}}$ & $7.1^{\mathrm{c}}$ \\
\hline 54 & $4.97^{\mathrm{c}}$ & $2.49^{\mathrm{c}}$ & $2.48^{\mathrm{d}}$ & $50.10^{\mathrm{a}}$ & $0.046^{\mathrm{b}}$ & $0.019^{\mathrm{c}}$ & $6.9^{\mathrm{e}}$ \\
\hline 60 & $5.21^{\mathrm{b}}$ & $2.57^{\mathrm{b}}$ & $2.64^{\mathrm{bc}}$ & $49.33^{\mathrm{b}}$ & $0.043^{\mathrm{d}}$ & $0.016^{\mathrm{d}}$ & $6.8^{\mathrm{f}}$ \\
\hline 72 & $5.42^{\mathrm{a}}$ & $2.60^{\mathrm{a}}$ & $2.82^{\mathrm{a}}$ & $47.97^{\mathrm{c}}$ & $0.036^{\mathrm{f}}$ & $0.013^{\mathrm{e}}$ & $6.6^{\mathrm{g}}$ \\
\hline
\end{tabular}

PHAs content $(\%)=$ Polymer concentration $(\mathrm{g} / \mathrm{L}) /$ cell dry weight $(\mathrm{g} / \mathrm{L}) \mathrm{x} 100$.

Productivity $(\mathrm{g} / \mathrm{L} / \mathrm{h})=$ Polymer concentration $(\mathrm{g} / \mathrm{L}) /$ fermentation time $(\mathrm{h})($ Lee, 1996$)$.

PHAs synthesis rate $(\mathrm{g} / \mathrm{g} / \mathrm{h})=$ Polymer concentration $(\mathrm{g} / \mathrm{L}) /$ residual cells $(\mathrm{g} / \mathrm{L}) /$ fermentation time $(\mathrm{h})$ (Ramadan et al., 1985).

Values in the same column followed by the same letter do not significantly differ from each other, according to Duncan's at $5 \%$ level. 
Table 4 - Impact of time course on the PHAs parameters (CUE, yield, $\mu_{\mathrm{p}}$ and CC) produced by Ps. fluorescens $\mathrm{S} 48$ on productive medium containing WFO as carbon source throughout $72 \mathrm{~h}$ at $30^{\circ} \mathrm{C}$ using bioreactor as a two-stage batch culture.

\begin{tabular}{|c|c|c|c|c|c|c|c|c|}
\hline Time (h) & $\begin{array}{c}\text { Cell dry } \\
\text { weight }(\mathrm{g} / \mathrm{L})\end{array}$ & $\begin{array}{l}\text { PHAs concentra- } \\
\text { tion }(\mathrm{g} / \mathrm{L})\end{array}$ & $\begin{array}{l}\text { Carbon concen- } \\
\text { tration }(\mathrm{g} / \mathrm{L})\end{array}$ & $\begin{array}{l}\text { Utilized car- } \\
\text { bon(UC)(g/L) }\end{array}$ & $\begin{array}{l}\text { Carbon utiliza- } \\
\text { tion efficiency } \\
\text { (CUE) }(\%)\end{array}$ & $\begin{array}{l}\text { Yield (Y) } \\
(\%)\end{array}$ & $\begin{array}{l}\text { Specific produc- } \\
\text { tion rate }\left(\mu_{\mathrm{p}}\right) \\
\left(\mathrm{h}^{-1}\right)\end{array}$ & $\begin{array}{l}\text { Conversion coef- } \\
\text { ficient }(\mathrm{CC})(\%)\end{array}$ \\
\hline 0 & $0.92^{\mathrm{j}}$ & $0.00^{\mathrm{i}}$ & $7.60^{\mathrm{a}}$ & $0.00^{\mathrm{j}}$ & $0.00^{\mathrm{j}}$ & $0.00^{\mathrm{i}}$ & $0.000^{\mathrm{h}}$ & $0.00^{\mathrm{i}}$ \\
\hline 6 & $1.32^{\mathrm{i}}$ & $0.00^{\mathrm{i}}$ & $7.07^{\mathrm{b}}$ & $0.53^{\mathrm{i}}$ & $6.97^{\mathrm{i}}$ & $0.00^{\mathrm{i}}$ & $0.000^{\mathrm{h}}$ & $0.00^{\mathrm{i}}$ \\
\hline 12 & $1.99^{\mathrm{h}}$ & $0.23^{\mathrm{h}}$ & $5.78^{\mathrm{c}}$ & $1.82^{\mathrm{h}}$ & $23.95^{\mathrm{h}}$ & $3.03^{\mathrm{h}}$ & $0.000^{\mathrm{h}}$ & $12.64^{\mathrm{h}}$ \\
\hline 24 & $2.94^{\mathrm{g}}$ & $0.92^{\mathrm{g}}$ & $5.40^{\mathrm{d}}$ & $2.20^{\mathrm{g}}$ & $28.95^{\mathrm{g}}$ & $12.11^{\mathrm{g}}$ & $0.116^{\mathrm{a}}$ & $41.82^{\mathrm{a}}$ \\
\hline 30 & $3.12^{\mathrm{f}}$ & $1.32^{\mathrm{f}}$ & $2.48^{\mathrm{e}}$ & $5.12^{\mathrm{f}}$ & $67.37^{\mathrm{f}}$ & $17.37^{\mathrm{f}}$ & $0.097^{\mathrm{b}}$ & $25.78^{\mathrm{g}}$ \\
\hline 36 & $3.64^{\mathrm{e}}$ & $1.72^{\mathrm{e}}$ & $1.68^{\mathrm{f}}$ & $5.92^{\mathrm{e}}$ & $77.89^{\mathrm{e}}$ & $22.63^{\mathrm{e}}$ & $0.084^{\mathrm{c}}$ & $29.05^{\mathrm{f}}$ \\
\hline 48 & $4.82^{\mathrm{d}}$ & $2.13^{\mathrm{d}}$ & $1.29^{\mathrm{g}}$ & $6.31^{\mathrm{d}}$ & $83.03^{\mathrm{d}}$ & $28.03^{\mathrm{d}}$ & $0.062^{\mathrm{d}}$ & $33.76^{\mathrm{e}}$ \\
\hline 54 & $4.97^{\mathrm{c}}$ & $2.49^{\mathrm{c}}$ & $0.66^{\mathrm{h}}$ & $6.94^{\mathrm{c}}$ & $91.32^{\mathrm{c}}$ & $32.76^{\mathrm{c}}$ & $0.057^{\mathrm{e}}$ & $35.88^{\mathrm{b}}$ \\
\hline 60 & $5.21^{\mathrm{b}}$ & $2.57^{\mathrm{b}}$ & $0.28^{\mathrm{i}}$ & $7.32^{\mathrm{b}}$ & $96.32^{\mathrm{b}}$ & $33.82^{\mathrm{b}}$ & $0.050^{\mathrm{f}}$ & $35.11^{\mathrm{c}}$ \\
\hline 72 & $5.42^{\mathrm{a}}$ & $2.60^{\mathrm{a}}$ & $0.07^{\mathrm{g}}$ & $7.53^{\mathrm{a}}$ & $99.08^{\mathrm{a}}$ & $34.21^{\mathrm{a}}$ & $0.040^{\mathrm{g}}$ & $34.53^{\mathrm{d}}$ \\
\hline
\end{tabular}

Carbon utilization efficiency $(\%)=$ Utilized carbon $(\mathrm{g} / \mathrm{L}) /$ initial carbon $(\mathrm{g} / \mathrm{L}) \mathrm{X} 100$ (Ramadan et al., 1985).

Yield $=$ PHAs $(\mathrm{g} / \mathrm{L}) /$ initial carbon $(\mathrm{g} / \mathrm{L}) \times 100$ (Ramadan et al., 1985).

Conversion coefficient (\%): Polymer concentration (g/L) / utilized carbon (g/L) X 100 (Ramadan et al., 1985).

Specific production rate $\left(\mu_{\mathrm{p}}\right)\left(\mathrm{h}^{-1}\right)=\mathrm{Ln}$ polymer concentration $(\mathrm{g} / \mathrm{L})$ at $(\mathrm{T})$ - Ln polymer concentration $(\mathrm{g} / \mathrm{L})$ at $\left(\mathrm{T}_{0}\right) / \mathrm{T}-\mathrm{T}_{0}($ Ramadan et al., 1985).

Values in the same column followed by the same letter do not significantly differ from each other, according to Duncan's at $5 \%$ level.

during the first $24 \mathrm{~h}$ of fermentation and then gradually decreased to reach 6.6 after $72 \mathrm{~h}$. The highest values of UC, CUE and polymer yield were recorded at the end of fermentation period $(7.53 \mathrm{~g} / \mathrm{L}, 99.08 \%$ and $34.21 \%$, respectively). The corresponding figures of conversion coefficient of WFO carbon was $34.53 \%$.

\section{High cell density fed-batch culture}

Using the previous improved results, further optimizations were done using the same fed-batch technique with continuous WFO feeding at $0.55 \mathrm{~mL} / \mathrm{L} / \mathrm{h}$ but with scaled up the volume of the bioreactor to $14 \mathrm{~L}$. Aiming to reach a higher cell density and polymer productivity. Data given in Tables 5 and 6 show that the maximum values of cell dry weight of Ps. fluorescens S48, PHAs concentration, content, yield and conversion coefficient were obtained after $54 \mathrm{~h}(4.21 \mathrm{~g} / \mathrm{L}, 2.33 \mathrm{~g} / \mathrm{L}, 55.34 \%, 29.91 \%$ and $33.87 \%$, respectively), with initial cell dry weight of $0.64 \mathrm{~g} / \mathrm{L}$ and WFO continuous feeding rate at $0.55 \mathrm{~mL} / \mathrm{L} / \mathrm{h}$. At this time, the polymer productivity was $0.043 \mathrm{~g} / \mathrm{L} / \mathrm{h}$. The highest specific production rate of PHAs was obtained during the first $12 \mathrm{~h}$ of fermentation period being $0.224 \mathrm{~h}^{-1}$, whereas, the maximum UC and CUE were noticed after $72 \mathrm{~h}(7.55 \mathrm{~g} / \mathrm{L}$ and $96.92 \%$, respectively).

Table 5 - Semi-scale production of PHAs by Ps. fluorescens S48 on productive medium containing WFO as carbon source throughout $72 \mathrm{~h}$ at $30^{\circ} \mathrm{C}$ using bioreactor as high-cell-density fed-batch culture with $0.64 \mathrm{~g} / \mathrm{L}$ cell density and continuous WFO feeding at $0.55 \mathrm{~mL} / \mathrm{L} / \mathrm{h}$.

\begin{tabular}{|c|c|c|c|c|c|c|c|c|c|}
\hline Time (h) & $\begin{array}{l}\text { Added WFO } \\
(\mathrm{mL} / \mathrm{L})\end{array}$ & $\begin{array}{l}\text { Added car- } \\
\text { bon }(\mathrm{g} / \mathrm{L})\end{array}$ & $\begin{array}{c}\text { Cell dry } \\
\text { weight }(\mathrm{g} / \mathrm{L})\end{array}$ & $\begin{array}{l}\text { PHAs concentra- } \\
\text { tion }(\mathrm{g} / \mathrm{L})\end{array}$ & $\begin{array}{l}\text { Residual } \\
\text { cells }(\mathrm{g} / \mathrm{L})\end{array}$ & $\begin{array}{l}\text { PHAs con- } \\
\text { tent }(\%)\end{array}$ & $\begin{array}{l}\text { PHAs productiv- } \\
\text { ity }(\mathrm{g} / \mathrm{L} / \mathrm{h})\end{array}$ & $\begin{array}{l}\text { PHAs synthesis } \\
\text { rate }(\mathrm{g} / \mathrm{g} / \mathrm{h})\end{array}$ & Final $\mathrm{pH}$ \\
\hline 0 & $0.00^{\mathrm{d}}$ & $0.00^{\mathrm{d}}$ & $0.64^{\mathrm{j}}$ & $0.00^{\mathrm{j}}$ & $0.64^{\mathrm{j}}$ & $0.00^{\mathrm{j}}$ & $0.000^{\mathrm{h}}$ & $0.000^{\mathrm{i}}$ & $7.0^{\mathrm{d}}$ \\
\hline 6 & $3.30^{\mathrm{c}}$ & $2.57^{\mathrm{c}}$ & $1.01^{\mathrm{i}}$ & $0.06 \mathrm{i}$ & $0.95^{\mathrm{i}}$ & $5.94^{\mathrm{i}}$ & $0.010^{\mathrm{g}}$ & $0.011^{\mathrm{g}}$ & $7.2^{\mathrm{b}}$ \\
\hline 12 & $6.60^{\mathrm{b}}$ & $5.15^{\mathrm{b}}$ & $1.30^{\mathrm{h}}$ & $0.23^{\mathrm{h}}$ & $1.07^{\mathrm{h}}$ & $17.69^{\mathrm{h}}$ & $0.019^{\mathrm{f}}$ & $0.018^{\mathrm{e}}$ & $7.2^{\mathrm{b}}$ \\
\hline 24 & $9.99^{\mathrm{a}}$ & $7.79^{\mathrm{a}}$ & $1.98^{\mathrm{g}}$ & $0.58^{\mathrm{g}}$ & $1.40^{\mathrm{g}}$ & $29.29^{\mathrm{g}}$ & $0.024^{\mathrm{e}}$ & $0.017^{\mathrm{f}}$ & $7.3^{\mathrm{a}}$ \\
\hline 30 & $9.99^{\mathrm{a}}$ & $7.79^{\mathrm{a}}$ & $2.13^{\mathrm{f}}$ & $0.71^{\mathrm{f}}$ & $1.42^{\mathrm{f}}$ & $33.33^{\mathrm{f}}$ & $0.024^{\mathrm{e}}$ & $0.017^{\mathrm{f}}$ & $7.2^{\mathrm{b}}$ \\
\hline 36 & $9.99^{\mathrm{a}}$ & $7.79^{\mathrm{a}}$ & $2.42^{\mathrm{e}}$ & $0.97^{\mathrm{e}}$ & $1.45^{\mathrm{e}}$ & $39.98^{\mathrm{e}}$ & $0.027^{\mathrm{d}}$ & $0.019^{d}$ & $7.3^{\mathrm{a}}$ \\
\hline 48 & $9.99^{\mathrm{a}}$ & $7.79^{\mathrm{a}}$ & $3.98^{\mathrm{c}}$ & $2.17^{\mathrm{c}}$ & $1.81^{\mathrm{d}}$ & $54.52^{\mathrm{c}}$ & $0.045^{\mathrm{a}}$ & $0.025^{\mathrm{a}}$ & $7.1^{\mathrm{c}}$ \\
\hline 54 & $9.99^{\mathrm{a}}$ & $7.79^{\mathrm{a}}$ & $4.21^{\mathrm{a}}$ & $2.33^{\mathrm{a}}$ & $1.88^{\mathrm{b}}$ & $55.34^{\mathrm{a}}$ & $0.043^{\mathrm{b}}$ & $0.023^{\mathrm{b}}$ & $6.9^{\mathrm{e}}$ \\
\hline 60 & $9.99^{\mathrm{a}}$ & $7.79^{\mathrm{a}}$ & $4.11^{\mathrm{b}}$ & $2.26^{\mathrm{b}}$ & $1.85^{\mathrm{c}}$ & $54.99^{\mathrm{b}}$ & $0.038^{\mathrm{c}}$ & $0.020^{\mathrm{c}}$ & $6.8^{\mathrm{f}}$ \\
\hline 72 & $9.99^{\mathrm{a}}$ & $7.79^{\mathrm{a}}$ & $3.32^{\mathrm{d}}$ & $1.39^{\mathrm{d}}$ & $1.93^{\mathrm{a}}$ & $41.87^{\mathrm{d}}$ & $0.019^{\mathrm{f}}$ & $0.010^{\mathrm{h}}$ & $6.6^{\mathrm{g}}$ \\
\hline
\end{tabular}

PHAs content $(\%)=$ Polymer concentration $(\mathrm{g} / \mathrm{L}) /$ Cell dry weight $(\mathrm{g} / \mathrm{L}) \times 100$.

PHAs productivity $(\mathrm{g} / \mathrm{L} / \mathrm{h})=$ Polymer concentration $(\mathrm{g} / \mathrm{L}) /$ Fermentation time $(\mathrm{h})($ Lee, 1996).

PHAs synthesis rate $(\mathrm{g} / \mathrm{g} / \mathrm{h})=$ Polymer concentration $(\mathrm{g} / \mathrm{L}) /$ Residual cells $(\mathrm{g} / \mathrm{L}) /$ Fermentation time (h) (Ramadan et al., 1985)

Values in the same column followed by the same letter do not significantly differ from each other, according to Duncan's at $5 \%$ level. 
Table 6 - Impact of time course on the PHAs parameters (CUE, yield, $\mu_{\mathrm{p}}$ and CC) produced by Ps. fluorescens S48 on productive medium containing WFO as carbon source throughout $72 \mathrm{~h}$ at $30^{\circ} \mathrm{C}$ using bioreactor as high-cell-density fed-batch culture with $0.64 \mathrm{~g} / \mathrm{L}$ cell density and continuous WFO feeding at $0.55 \mathrm{~mL} / \mathrm{L} / \mathrm{h}$.

\begin{tabular}{|c|c|c|c|c|c|c|c|c|c|c|}
\hline Time (h) & $\begin{array}{c}\text { Added } \\
\text { WFO } \\
(\mathrm{mL} / \mathrm{L})\end{array}$ & $\begin{array}{l}\text { Added car- } \\
\text { bon }(g / L)\end{array}$ & $\begin{array}{c}\text { Cell dry } \\
\text { weight }(\mathrm{g} / \mathrm{L})\end{array}$ & $\begin{array}{l}\text { PHAs con- } \\
\text { centration } \\
\quad(\mathrm{g} / \mathrm{L})\end{array}$ & $\begin{array}{l}\text { Carbon con- } \\
\text { centration } \\
(\mathrm{g} / \mathrm{L})\end{array}$ & $\begin{array}{l}\text { Utilized car- } \\
\text { bon (UC) } \\
(\mathrm{g} / \mathrm{L})\end{array}$ & $\begin{array}{c}\text { Carbon uti- } \\
\text { lization effi- } \\
\text { ciency } \\
\text { (CUE) }(\%)\end{array}$ & $\begin{array}{c}\text { Yield (Y) } \\
(\%)\end{array}$ & $\begin{array}{c}\text { Specific } \\
\text { production } \\
\text { rate }\left(\mu_{\mathrm{p}}\right) \\
\left(\mathrm{h}^{-1}\right)\end{array}$ & $\begin{array}{c}\text { Conversion } \\
\text { coefficient } \\
\text { (CC) }(\%)\end{array}$ \\
\hline 0 & $0.00^{\mathrm{d}}$ & $0.00^{\mathrm{d}}$ & $0.64^{\mathrm{j}}$ & $0.00^{\mathrm{j}}$ & $0.00^{\mathrm{j}}$ & $0.00^{\mathrm{j}}$ & $0.00^{\mathrm{j}}$ & $0.00^{\mathrm{j}}$ & $0.000^{\mathrm{i}}$ & $0.00^{\mathrm{j}}$ \\
\hline 6 & $3.30^{\mathrm{c}}$ & $2.57^{\mathrm{c}}$ & $1.01^{\mathrm{i}}$ & $0.06^{\mathrm{i}}$ & $1.01^{\mathrm{f}}$ & $1.56^{\mathrm{i}}$ & $60.07^{\mathrm{h}}$ & $2.33^{\mathrm{i}}$ & $0.000^{\mathrm{i}}$ & $3.85^{\mathrm{i}}$ \\
\hline 12 & $6.60^{\mathrm{b}}$ & $5.15^{\mathrm{b}}$ & $1.30^{\mathrm{h}}$ & $0.23^{\mathrm{h}}$ & $1.07^{\mathrm{e}}$ & $4.08^{\mathrm{h}}$ & $79.22^{\mathrm{e}}$ & $4.47^{\mathrm{h}}$ & $0.224^{\mathrm{a}}$ & $5.64^{\mathrm{h}}$ \\
\hline 24 & $9.99^{\mathrm{a}}$ & $7.79^{\mathrm{a}}$ & $1.98^{\mathrm{g}}$ & $0.58^{\mathrm{g}}$ & $3.21^{\mathrm{a}}$ & $4.58^{\mathrm{g}}$ & $58.79^{\mathrm{i}}$ & $7.45^{\mathrm{g}}$ & $0.126^{\mathrm{b}}$ & $12.66^{\mathrm{g}}$ \\
\hline 30 & $9.99^{\mathrm{a}}$ & $7.79^{\mathrm{a}}$ & $2.13^{\mathrm{f}}$ & $0.71^{\mathrm{f}}$ & $2.48^{\mathrm{b}}$ & $5.31^{\mathrm{f}}$ & $68.16^{\mathrm{g}}$ & $9.11^{\mathrm{f}}$ & $0.103^{\mathrm{c}}$ & $13.37^{\mathrm{f}}$ \\
\hline 36 & $9.99^{\mathrm{a}}$ & $7.79^{\mathrm{a}}$ & $2.42^{\mathrm{e}}$ & $0.97^{\mathrm{e}}$ & $1.68^{\mathrm{c}}$ & $6.11^{\mathrm{e}}$ & $78.43^{\mathrm{f}}$ & $12.45^{\mathrm{e}}$ & $0.093^{\mathrm{d}}$ & $15.88^{\mathrm{e}}$ \\
\hline 48 & $9.99^{\mathrm{a}}$ & $7.79^{\mathrm{a}}$ & $3.98^{\mathrm{c}}$ & $2.17^{\mathrm{c}}$ & $1.29^{\mathrm{d}}$ & $6.50^{\mathrm{d}}$ & $83.44^{\mathrm{d}}$ & $27.86^{\mathrm{c}}$ & $0.085^{\mathrm{e}}$ & $33.38^{\mathrm{b}}$ \\
\hline 54 & $9.99^{\mathrm{a}}$ & $7.79^{\mathrm{a}}$ & $4.21^{\mathrm{a}}$ & $2.33^{\mathrm{b}}$ & $0.91^{\mathrm{g}}$ & $6.88^{\mathrm{c}}$ & $88.32^{\mathrm{c}}$ & $29.91^{\mathrm{a}}$ & $0.076^{\mathrm{f}}$ & $33.87^{\mathrm{a}}$ \\
\hline 60 & $9.99^{\mathrm{a}}$ & $7.79^{\mathrm{a}}$ & $4.11^{\mathrm{b}}$ & $2.26^{\mathrm{a}}$ & $0.62^{\mathrm{h}}$ & $7.17^{\mathrm{b}}$ & $92.04^{\mathrm{b}}$ & $29.01^{\mathrm{b}}$ & $0.067^{\mathrm{g}}$ & $31.52^{\mathrm{c}}$ \\
\hline 72 & $9.99^{\mathrm{a}}$ & $7.79^{\mathrm{a}}$ & $3.32^{\mathrm{d}}$ & $1.39^{\mathrm{d}}$ & $0.24^{\mathrm{i}}$ & $7.55^{\mathrm{a}}$ & $96.92^{\mathrm{a}}$ & $17.84^{\mathrm{d}}$ & $0.048^{\mathrm{h}}$ & $18.41^{\mathrm{d}}$ \\
\hline
\end{tabular}

Carbon utilization efficiency $(\%)=$ Utilized carbon $(\mathrm{g} / \mathrm{L}) /$ initial carbon $(\mathrm{g} / \mathrm{L}) \mathrm{X} 100$ (Ramadan et al., 1985).

Yield = PHAs $(\mathrm{g} / \mathrm{L}) /$ initial carbon $(\mathrm{g} / \mathrm{L}) \times 100$ (Ramadan et al., 1985).

Productivity $(\mathrm{g} / \mathrm{L} / \mathrm{h})=$ Polymer concentration $(\mathrm{g} / \mathrm{L}) /$ fermentation time $(\mathrm{h})(\mathrm{Lee}, 1996)$.

Conversion coefficient $(\%)=$ Polymer concentration $(\mathrm{g} / \mathrm{L}) /$ utilized carbon $(\mathrm{g} / \mathrm{L})$ X 100 (Ramadan et al., 1985).

Values in the same column followed by the same letter do not significantly differ from each other, according to Duncan's at $5 \%$ level.

In the previous study fed-batch fermentation (bioreactor 3 L) Gamal et al. (2012), a relatively high cell dry weight and high polymer content were achieved after a short incubation time $(48 \mathrm{~h})$. Both were higher by a factor of 2.4 and 4.14, respectively, than those recorded in shake flask experiments after $72 \mathrm{~h}$ (Gamal et al., 2011). Also, it could be noticed that the application of high cell density fed-batch culture in $10 \mathrm{~L}$ fermentation medium (bioreactor $14 \mathrm{~L}$ ) increased the PHAs content by about $84 \%$ and $16.82 \%$ than that obtained by batch and two-stage batch cultures (bioreactor 3 L) Gamal et al. (2012), respectively, as well as shortened the fermentation period by about $6 \mathrm{~h}$ comparing with batch culture. Also it could be stated that using the $10 \mathrm{~L}$ fermentation culture led to increase the PHAs content of one-stage batch, two-stage batch and high cell density fed batch cultures about $12.3 \%, 5.8 \%$ and $11.3 \%$, respectively, than that obtained by $3 \mathrm{~L}$ fermentation culture (Table 7). These results are in line with those obtained by Valappil et al. (2007), they stated that a simple glucose feeding strategy in $20 \mathrm{~L}$ batch fermentation increased the polymer yield by $31 \%$ compared to the batch culture. Additionally, Riesenberg and Guthke (1999) stated that high cell density cultivations represented an about 10-20 fold increase in growth in comparison to normal cell density growth. Problems encountered by high cell density cultivation are numerous, such as $\mathrm{PO}_{2}$ deficiency, byproduct formation, and/or metabolic heat production. As a result of the growing industrial interest in high cell density, many attempts have been made to improve high cell density fermentations, such as improving potent strain, and/or applying different types of bioreactors and cultivation strategies.

\section{PHAs recovery}

One of the most important prerequisites for an industrial strain for PHA production is how easy PHA can be recovered from non-PHA cell matter (Suriyamongkol et al., 2007). Although several new downstream processes for the extraction of PHAs have been reported as economically effective, such as the application of surfactants and the dispersions of hypochlorite solution and chloroform, solvent extraction methods are still regarded as an adequate way to gain intact polymer with high purity and recovery yield (Ramsay et al., 1990). The organic solvents were investigated to determine their efficiency to recover PHAs and how easy the separation of them from cells debris after extraction could be. Data illustrated in Figure 1 show that the maximum efficiency of solvent recovery of PHA was attained by chloroform-hypochlorite dispersion extraction (method 2, 55\%) followed by that extracted with chloroform $60{ }^{\circ} \mathrm{C}$ for $1 \mathrm{~h}$ after pretreatment the cells with $10 \%$ SDS at $100^{\circ} \mathrm{C}$ for $20 \mathrm{~min}$ (method 6, 53\%). However, polymer recovery by hot acetone and chloroform (method 3 ) or sodium hypochlorite alone (method 4) gave the lowest PHA content ( $40 \%$ and $39 \%$, respectively). The corresponding figures of PHA concentration were 2.3, 2.0, 1.5 and $1.42 \mathrm{~g} / \mathrm{L}$, respectively. There is still a need to develop and improve these extraction methods further to make the entire processes much simpler and cheaper.

\section{Analysis of PHA by gas chromatography}

Gas chromatography (GC) analysis revealed that polyhydroxyalkanoates (PHAs) produced from Ps. fluorescens S48 was solely composed of 3-hydroxybutyric 


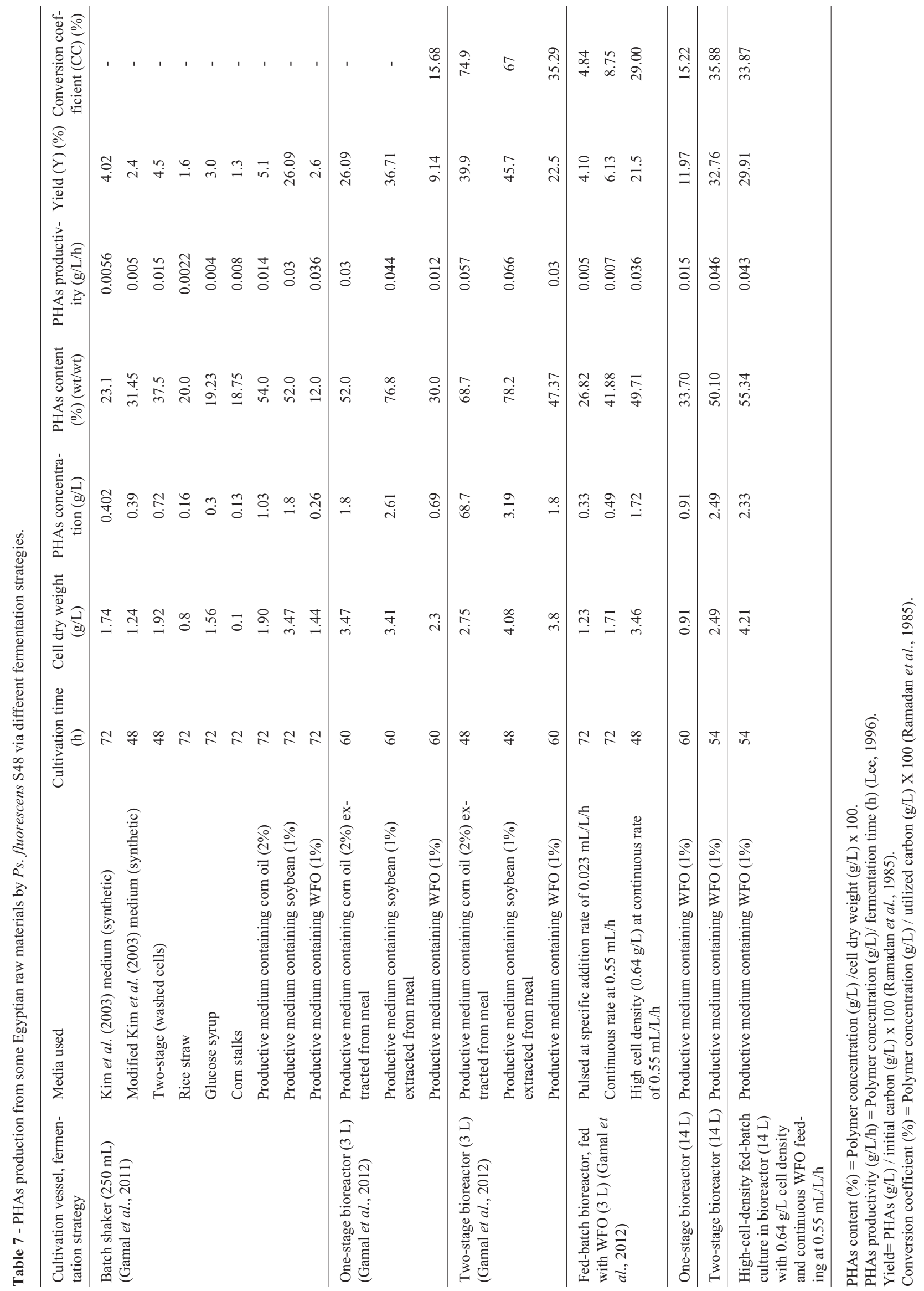




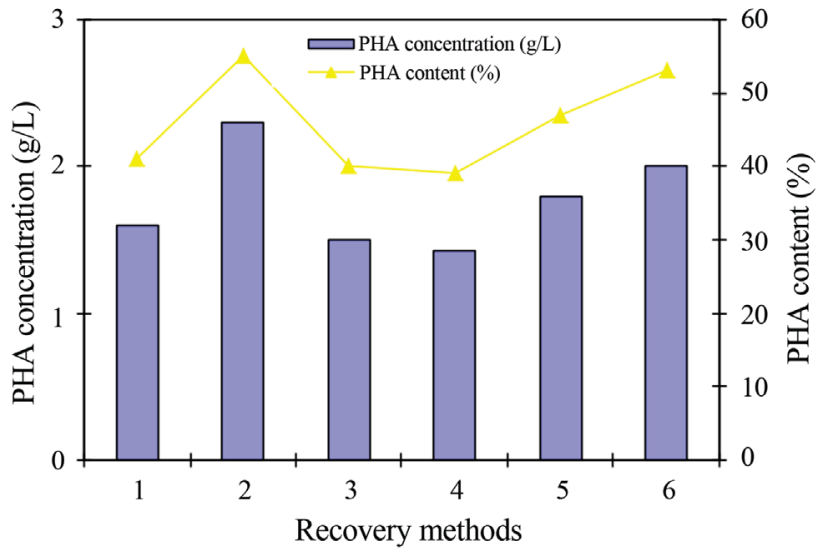

Figure 1 - Efficacy of different recovery methods (1-6) on PHAs extraction from Ps. fluorescens S48.

acid (98.7\%) (Figure 2). Therefore, this feature made them highly competitive with polyethylene and petrochemicalderived plastics. The biodegradable biopolymer (PHB) are often preferred materials not only for environmental considerations, but also in medical application such as developing therapeutic devices, for tissue engineering and for slow release drug delivery systems (Nair and Laurencin, 2007). The preparation of PHA polymer films which solely composed of 3-hydroxybutyric acid (98.7\%) was implemented according to Kai et al. (2003). A film made of PHB was shown in Figure 3.

\section{Genotypic characterization}

In case of genus Pseudomonas, nearly complete sequences have been determined for the PCR amplified 16S rRNA genes of about 21 species (Moore et al., 1999). In this report, we have further investigated the taxonomic position of the bacterial isolate Ps. fluorescens S48, which was proposed here to represent a species, upon sequencing most of the 16S rRNA gene, it was discovered that the isolate Ps. fluorescens S48 shares the same identical sequence, which is nearly the complete $16 \mathrm{~S}$ rRNA gene. The identity of this sequence to the closest Pseudomonads strains is about $98-99 \%$. Concerning the phylogenetic tree con-

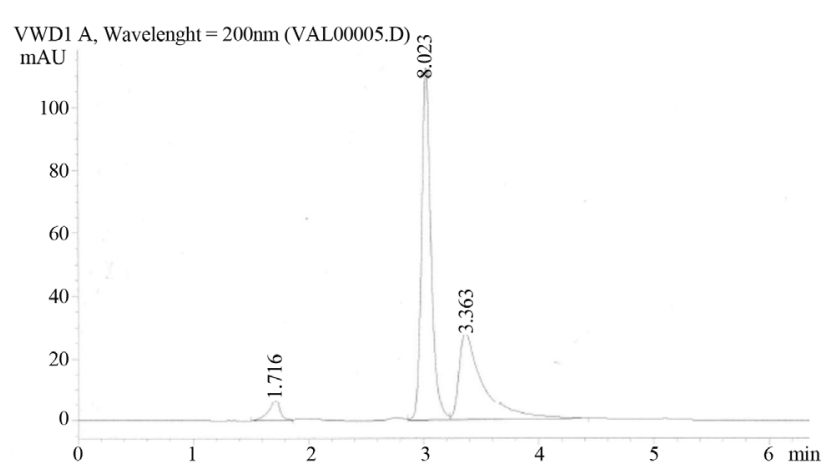

Figure 2 - Gas chromatography (GC) of 3HB-methyl ester indicating that the biopolymer produced by Ps. fluorescens S48 was solely composed of 3-hydroxybutyric acid.

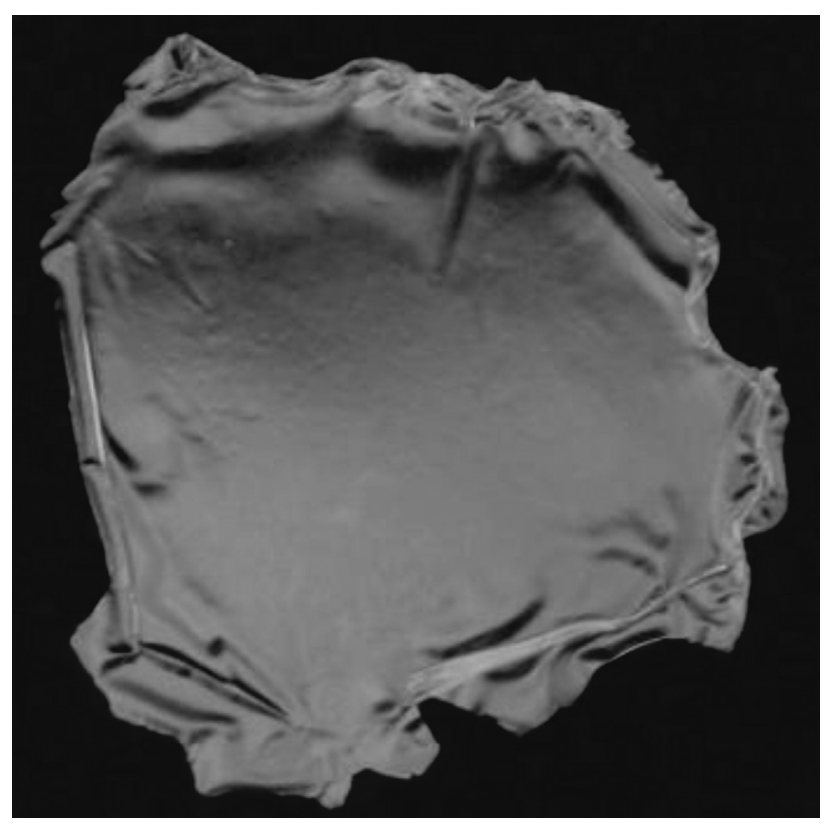

Figure 3 - Plastic film made of PHB produced by Ps. fluorescens S48.

structed in this study it was interesting to note that the isolate Ps. fluorescens S48 is so close to Egyptian strain named EG 639838 (Figure 4). Based on phylogenetic study, the analysis of the 16S rRNA gene sequences data for the isolate Ps. fluorescens share the same sequence, but

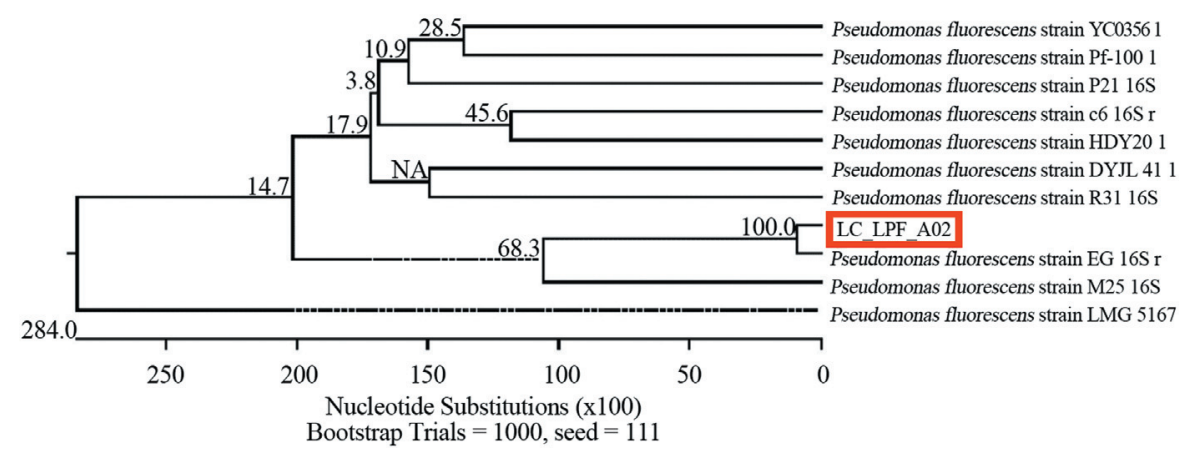

Figure 4 - Neighbor-joining tree showing the estimated phylogenetic relationships of the isolated strain (shown in red) and other closely-related strains of the genus Pseudomonas based on comparative analysis of $16 \mathrm{~S}$ RNA sequences. 
slightly differ from another Pseudomonas species. The strain studied was probably closely related to support another meaningful parsimony analysis and construction of a phylogenetic tree. The genetic relationships between the Ps. fluorescens S48 and known members of other species of Pseudomonas genus were estimated by parsimony analysis (Swofford, 1993) using haustoric search with TBR branch swapping (100 replicates). The bootstrap analyses were run with TBR MULPARS and 1000 replicates.

\section{Acknowledgments}

The authors are pleased to acknowledge Science and Technology Development Fund (STDF) for financial support.

\section{References}

Abdel Hafez AM, Abdelhady Hemmat M, El-Sayed AA, Khodair TA (2009) Fermentative production of polyhydroxybutyrate (PHB) by high cell density culture of $R$. eutropha and $A$. latus in $\mathrm{pH}$-stat fed-batch culture. J Biol Chem Environ Sci 4:93-107.

Altschul SF, Madden TL, Schaffer AA, Zhang J, Zhang Z, Miller W, Lipman DJ (1997) Gapped BLAST and PSIBLAST: A new generation of protein database search programs. Nucleic Acids Res 25:3389-3402.

Da Silva GP, Mack M, Contiero J (2009) Glycerol: A promising and abundant carbon source for industrial microbiology. Biotechnol Adv 27:30-39.

Gamal RF, Abdelhady HM, Hassan EA, El-Tayeb TS, Aboutaleb KA (2011) Production of Polyhydroxyalkanoate (PHAs) and Copolymer [P(HB-co-HV)] by soil bacterial isolates in batch and two-stage batch cultures. Egypt J Microbiol 46:85-90.

Gamal RF, Abdelhady HM, Hassan EA, El-Tayeb TS, Aboutaleb KA (2012) Production of PHAs from waste frying oil by Pseudomonas fluorescens S48 using different bioreactor feeding strategies. Egypt J Microbiol 47:130-136.

Hahn SK, Chang YK, Kim BS, Chang HN (1994) Optimization of microbial poly (3-hydroxybutarate) recovery using dispersions of sodium hypochlorite solution and chloroform. Biotechnol Bioeng 44:256-261.

Hahn SK, Chang YK, Lee SY (1995) Recovery and characterization of poly(3-hydroxybutyric acid) synthesized in Alcaligenus eutrophus and Recombinant Escherichia coli. Appl Environ Microbial 61:34-39.

IBM $^{\circledR}$ SPSS $^{\circledR}$ Statistics (2011) Version 19.0, SPSS Inc., Chicago, Illinois.

Jiang Y, Song X, Gong L, Li P, Dai C, Shao W (2008) High poly ( $\beta$-hydroxybutyrate) production by Pseudomonas fluorescens A2a5 from inexpensive substrates. Enzym Microb Technol 42:167-172.

Kai Z, Ying D, Guo-Qiang CH (2003) Effects of surface morphology on the biocompatibility of polyhydroxyalkanoates. Biochem Eng J 16:115-123.

Kim BS, Lee SC, Lee SY, Chang HN, Chang YK, Woo SI (1994) Production of poly $\beta$ (3-hydroxybutyric acid) by fed-batch culture of Alcaligenes eutrophus with glucose concentration control. Biotechnol Bioeng 43:892-898.
Kim M, Cho KS, Ryu HW, Lee EG, Chang YK (2003) Recovery of poly (3-hydroxybutyrate) from high cell density culture of Ralstonia eutropha by direct addition of sodium dodecyl sulfate. Biotechnol Lett 25:55-59.

Kinoshita K, Yanagida Y, Osakada F, Ueda Y, Narasimhan K, Cearley A, Yee K, Noda I (2005) Method for producing polyhydroxyalkanoates. US patent application US0239998.

Lane DJ (1991) 16S/23S rRNA sequencing. In: E. Stackebrandt and M. Goodfellow, Editors, Nucleic Acid Techniques in Bacterial Systematics. John Wiley \& Sons, Inc., New York, pp 115-148.

Lane DJ, Pace BG, Olsen J, Stahl DA, Sogin ML, Pace NR (1985) Rapid determination of $16 \mathrm{~S}$ ribosomal RNA sequences for phylogenetic analyses. Proc Natl Acad Sci USA 82:69556959.

Law JH, Slepecky RA (1961) Assay of poly $\beta$ hydroxybutyric acid. J Bacteriol 82:33-36.

Lee SY (1996) Plastic bacteria. Progress and prospects for polyhydroxyalkanoate production in bacteria. Trends Biotechnol 14:431-438.

Lee SY, Choi J (1998) Polyhydroxyalkanoates biodegradable polymer. In: Manual of Industrial Microbiology and Biotechnology. $2^{\text {nd }}$ edition. Demain AL, Davies JE (eds). ASM Press, Washington D.C., pp. 616-627.

Lee SY, Middelberg AP, Lee YK (1997) Poly(hydro-xybutytrate) production from whey using recombinant Escherichia coli. Biotechnol Lett 19:1033-1035.

Lee YW, Yoo YJ (1994) High cell density culture of Alcaligenes eutrophus and poly- $\beta$-hydroxybutyrate production by optimization of medium compositions. J Appl Microbiol Biotechnol 22:401-406.

Lopez-Cuellar MR, Alba-Flores J, Gracida Rodrîguez JN, PérezGuevara F (2011) Production of polyhydroxyalkanoates (PHAs) with canola oil as carbon source. Inter J Biol Macromol 48:74-80.

Moore E, Arnscheidt A, Kruger A, Stromple C, Mau M (1999) Simplified protocols for the preparation of genomic DNA from bacterial cultures. In: Molecular Microbial Ecology Manual, 1.6.1. Akkermans ADL, van Elsas JD, de Bruijn FJ (eds) Kluwer Academic Press, Dordrecht, pp 1-15.

Mumtaz TS, Abd-Aziz N, Abdul Rahman P, Yee L, Shirai Y, Hassan MA (2009) Fed-batch Production of P(3HB-co3HV) Copolymer by Comamonas sp. EB 172 Using Mixed Organic Acids Under Dual Nutrient Limitation. Eur Sci Res 33:374-384.

Nair LS, Laurencin CT (2007) Biodegradable polymers as biomaterials. Prog Polym Sci 32:762-798.

Ramadan EM, El-Sawy M, Gamal RF, Abdelhady HM (1985) Growth parameters of yeast grown on agricultural residues using shake flasks as a batch culture. Annals Agric Sci, Fac Agri, Ain Shams Univ 30:25-45.

Ramsay BA, Lomaliza K, Chavarie C, Dube B, Bataille P, Ramsay JA (1990) Production of Poly-( $\beta$-hydroxybutyric-co- $\beta$ hydroxyvaleric) acids. Appl Environ Microbiol 56:20932098.

Riesenberg D, Guthke R (1999) High-cell-density cultivation of microorganisms. Appl Microbiol Biotechnol 51:350-360.

Simon-Colin C, Raguénès G, Costa B, Guezennec J (2008) Biosynthesis of medium chain lengthpoly-3-hydroxyalkanoates by Pseudomonas guezennei from various carbon sources. React Funct Polym 68:1534-1541. 
Slater S, Houmiel KL, Tran M, Mitsky TA, Taylor NB, Padgette SR, Gruys KJ (1998) Multiple beta-ketothiolases mediate poly (beta-hydroxyalkanoate) copolymer synthesis in Ralstonia eutropha. J Bacteriol 180:1979-1987.

Suriyamongkol PF, Weselake R, Narine S, Moloney M, Shah S (2007) Biotechnological approaches for the production of polyhydroxyalkanoates in microorganisms and plants. A review. Biotechnol Adv 25:148-175.

Swofford DL (1993) PAUP: Phylogenetic analysis using parsimony, version 3.1.1. Illinois Natural History Survey, Champaign.

Valappil SP, Misra SK, Boccaccini AR, Keshavarz T, Bucke C, Roy I (2007) Large-scale production and efficient recovery of PHB with desirable material properties, from the newly characterized Bacillus cereus SPV. J Biotechnol 132:251258 .
Vinnere O, Fatehi J, Wright SAI, Gerhardson B (2002) The causal agent of anthracnose of Rhododendron in Sweden and Latvia. Mycol Res 106:60-69.

Verlinden RAJ, Hill DJ, Kenward MA, Williams CD, Radecka I (2007) Bacterial synthesis of biodegradable polyhydroxyalkanoates. J Appl Microbiol 102:1437-1449.

Walinga I, Novozamsky I, Houba VJG (1992) Spectrophotometric determination carbon of organic in soil. Commun Soil Sci Plant Anal 23:1935-1944.

Wang F, Lee SY (1997) Production of poly $\beta$ (3-hydroxybutyrate) by fed-batch culture of filamentation-suppressed recombinant Escherichia coli. Appl Environ Microbiol 63:47654769.

All the content of the journal, except where otherwise noted, is licensed under a Creative Commons License CC BY-NC. 